\title{
Pressure-independent effects of pharmacological stimulation of soluble guanylate cyclase on fibrosis in pressure-overloaded rat heart
}

\author{
Hiroyuki Masuyama ${ }^{1}$, Toshihiro Tsuruda ${ }^{1}$, Yoko Sekita ${ }^{1}$, Kinta Hatakeyama ${ }^{2}$, Takuroh Imamura ${ }^{1}$, Johji Kato ${ }^{3}$, \\ Yujiro Asada ${ }^{2}$, Johannes-Peter Stasch ${ }^{4}$ and Kazuo Kitamura ${ }^{1}$
}

Cardiac fibrosis is a hallmark of cardiovascular remodeling associated with hypertension. The purpose of this study was to explore the effect and mechanism of soluble guanylate cyclase (sGC) stimulator BAY 41-2272, leading to intracellular cyclic guanosine monophosphate (cGMP) elevation, on the remodeling process induced by pressure overload. Seven-week-old male Wistar rats with hypertension induced by suprarenal aortic constriction (AC) were treated orally with $2 \mathrm{mg} \mathrm{kg}^{-1} \mathrm{day}^{-1}$ of BAY 41-2272 for 14 days. BAY 41-2272 had no effects on blood pressure, but decreased AC-induced collagen accumulation in the left ventricle (LV), inhibiting the number of myofibroblasts and gene expressions of transforming growth factor- $\beta 1$ and type 1 collagen. In addition, the antifibrotic action of BAY 41-2272 was accompanied by reducing AC-induced angiotensin-converting enzyme (ACE) mRNA and its enzymatic activity, and angiotensin II concentration in LV. In cultured cardiac fibroblasts, BAY 41-2272 inhibited ACE synthesis and myofibroblast transformation, accompanied by elevating the intracellular cGMP concentration. These results suggest that SGC stimulator BAY 41-2272 might be effective to reduce fibrosis in hypertensive heart disease by attenuating angiotensin II generation through myofibroblast transformation.

Hypertension Research (2009) 32, 597-603; doi:10.1038/hr.2009.64; published online 8 May 2009

Keywords: angiotensin; cGMP; fibrosis; soluble guanylate cyclase

\section{INTRODUCTION}

Extracellular matrix mainly produced by fibroblasts is essential for organizing an elastic network of cardiocytes in the myocardium, while the structural and functional alteration of these cell types is important in the pathogenesis of hypertensive heart disease, characterized by the left ventricular (LV) hypertrophy and fibrosis. ${ }^{1-3}$ As excessive myocardial fibrosis is assumed to be a critical determinant of the deterioration of LV function ${ }^{4,5}$ and the cause of arrhythmias, ${ }^{6}$ regulating the proliferation and activation of fibroblasts would be an important therapeutic target in the disorder. The renin-angiotensin II (Ang II) system (RAS) is recognized to stimulate fibrosis, ${ }^{7}$ whereas the inhibition of either angiotensin-converting enzyme (ACE) or Ang II type 1 receptor has been shown to regress myocardial fibrosis in patients with hypertensive heart disease. ${ }^{5,8}$

Guanylate cyclase is an enzyme that converts guanosine triphosphate to cyclic guanosine monophosphate (cGMP). Both types of guanylate cyclase, particulate guanylate cyclase stimulated by atrial and brain natriuretic peptides, ${ }^{9-13}$ and soluble guanylate cyclase (sGC) activated by nitric oxide, ${ }^{9,14}$ are reported to attenuate cardiovascular remodeling by elevating intracellular cGMP levels. In an effort to develop agents activating sGC, BAY 41-2272 was identified as an orally active nitric oxide-independent stimulator of the sGC $\alpha 1$ subunit. ${ }^{15}$ We and others have shown the beneficial effects of this compound not only on hemodynamics, but also on cardiovascular remodeling. ${ }^{15-18}$ As sGC/cGMP activation has been shown to interfere with RAS, ${ }^{19,20}$ we tested the hypothesis that the direct stimulation of sGC with BAY 41-2272 could attenuate myocardial fibrosis by inhibiting RAS activation. In this study, we used rats with pressure overload induced by suprarenal aortic constriction (AC), a model of hypertensive heart disease accompanied by fibroblast and RAS activation. ${ }^{21}$

\section{METHODS}

This study was performed in accordance with the Animal Welfare Act and approval from the University of Miyazaki Institutional Animal Care and Use Committee (2006-014). This investigation also conformed to the Guide for the Care and Use of Laboratory Animals published by the US National Institutes of Health (NIH Publication No. 85-23, revised 1996).

${ }^{1}$ Department of Internal Medicine, Circulatory and Body Fluid Regulation, Faculty of Medicine, University of Miyazaki, Miyazaki, Japan; ${ }^{2}$ Department of Pathology, Faculty of Medicine, University of Miyazaki, Miyazaki, Japan; ${ }^{3}$ Frontier Science Research Center, University of Miyazaki, Miyazaki, Japan and ${ }^{4}$ PharmD at Cardiovascular Research, Bayer HealthCare, Aprather Weg 18a, Wuppertal, Germany

Correspondence: Dr T Tsuruda, Department of Internal Medicine, Circulatory and Body Fluid Regulation, Faculty of Medicine, University of Miyazaki, 5200 Kihara Kiyotake, Miyazaki 889-1692, Japan.

E-mail: ttsuruda@med.miyazaki-u.ac.jp

Received 22 October 2008; revised 27 February 2009; accepted 7 April 2009; published online 8 May 2009 


\section{Animal experiment}

Seven-week-old male Wistar rats (Charles River, Yokohama, Japan), weighing 200-250 g, were housed in a temperature and light-controlled room $\left(25 \pm 1^{\circ} \mathrm{C}\right.$; 12/12-h light/dark cycle) for 1 week before use, with free access to normal rat chow and water. The rats were divided into three groups: control group $(n=11)$ and two pressure-overloaded groups with $(n=21)$ or without $(n=15)$ BAY $41-$ 2272 treatment. Pressure overload was induced by abdominal AC at the suprarenal level, as described earlier. ${ }^{22}$ In brief, a 22-gauge needle was placed adjacent to the abdominal aorta proximal to the renal artery, and ligated tightly around the aorta and the adjacent needle. The needle was then removed, leaving the vessel constricted to the diameter of the needle. The control group underwent identical surgical procedures but without constriction of the aorta. BAY 41-2272 compound, supplied by Bayer HealthCare (Wuppertal, Germany), was given by gastric gavage at a sub-depressor dose of $2 \mathrm{mg} \mathrm{kg}^{-1}$ twice a day for 14 days. The dose of BAY 41-2272 was chosen according to our earlier study. ${ }^{18}$ The Datascience telemetric system (St Paul, MN, USA) was used to monitor the blood pressure of four unrestricted, conscious rats in each study group, as described earlier. ${ }^{23}$ After banding the abdominal aorta, the transmitter catheter (model TA11PA-C40) was inserted into the descending aorta through the left carotid artery, and then the transmitter was implanted in the peritoneal cavity. After surgery, each rat was kept in an individual cage placed on a telemetric receiver pad. Blood pressure and heart rate data were collected for $10 \mathrm{~s}$ every $15 \mathrm{~min}$ and daily averages were calculated. At day 14, rats were anesthetized with pentobarbital sodium and killed by drawing blood from the thoracic aorta. After the whole heart was weighed, LV was frozen in liquid nitrogen or fixed in $4 \%$ paraformaldehyde and embedded in paraffin wax.

\section{Immunohistochemistry and histological analysis}

Immunohistochemical staining for $\alpha$-smooth muscle actin ( $\alpha$-SMA) and ACE were performed as described earlier. ${ }^{18,24}$ Slides were stained with mouse anti- $\alpha$ SMA monoclonal antibody (1:200, Clone 1A4, DakoCytomation, Carpinteria, CA,
USA) or rabbit polyclonal antibody against ACE (1:100, Santa Cruz Biotechnology, Santa Cruz, CA, USA) overnight at $4{ }^{\circ} \mathrm{C}$. After the overnight reaction with antibodies, slide sections were incubated with EnVision+ (Dako) for $30 \mathrm{~min}$, visualized with $0.05 \%$ 3,3-diaminobenzidine containing hydrogen peroxide, and counterstained with hematoxylin. Myofibroblasts positive for $\alpha$-SMA were counted at $\times 200$ magnification. To detect collagen fibers, slides were incubated with $0.1 \%$ picrosirius red (Direct Red 80, Sigma, St Louis, MO, USA) dissolved in saturated picric acid for $10 \mathrm{~min}$, as described earlier. ${ }^{18}$ To measure cardiocyte size, cross-sectional areas of $\geqslant 50$ myocardial fibers were measured at the level of nuclei while omitting longitudinally or obliquely sectioned cells as described earlier. ${ }^{18}$ Magnitudes of perivascular fibrosis or collagen volume fraction in the interstitial space of myocardial fibers were also determined as described earlier. ${ }^{18}$

\section{Gene expression}

Gene expressions of transforming growth factor (TGF)- $\beta 1$, type 1 collagen and ACE in the LV were measured by real-time quantitative reverse transcriptionPCR (ABI Prism 7700 Sequence Detector, Applied Biosystems, Foster City, CA, USA). ${ }^{18,24}$ Total RNA Isolation Reagent (Invitrogen, Carlsbad, CA, USA) was used to extract $1 \mu \mathrm{g}$ of total RNA, which then underwent reverse transcription by means of SuperScript reverse transcriptase (Invitrogen) into cDNA. cDNA was then amplified with oligonucleotide forward and reverse primers and with probes labeled with 6-carboxy-fluorescencein as reporter fluorescence and 6carboxy-tetramethyl-rhodamine as quencher fluorescence. The oligonucleotide sequences are detailed in earlier reports. ${ }^{18,24,25}$ The PCR products were of the expected molecular sizes and the gene expression levels were standardized to those of $18 \mathrm{~S}$ rRNA.

\section{Cell culture}

Cardiac fibroblasts were isolated from 1- to 3-day-old neonatal Wistar rats as described earlier. ${ }^{18}$ The cells were grown on culture plates with Dulbecco's modified Eagle's medium containing $10 \%$ fetal bovine serum, $10 \mu \mathrm{gl}^{-1}$ a

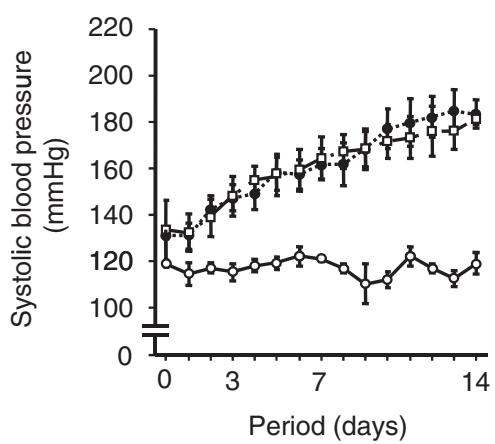

d

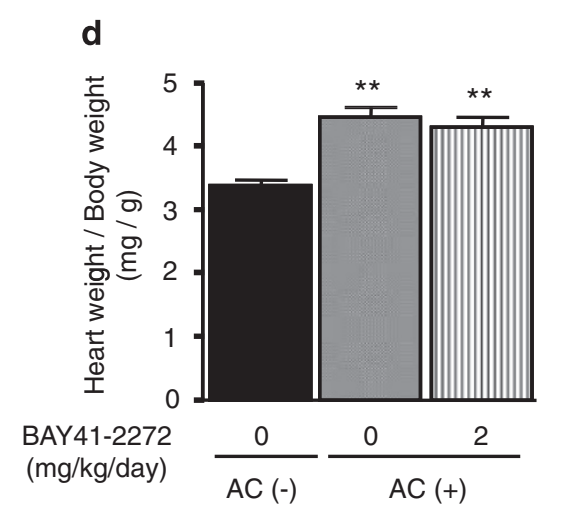

b

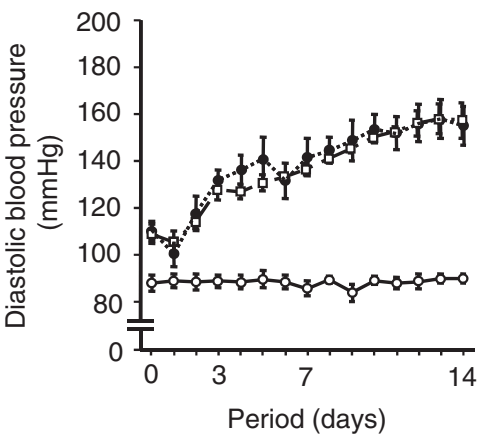

C

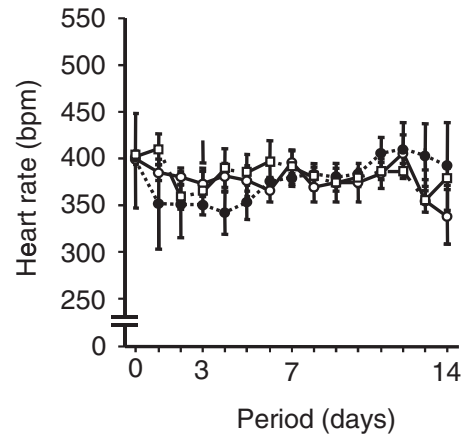

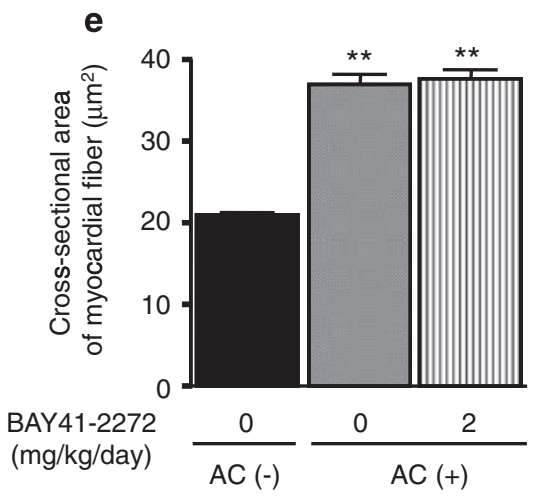

Control

- $A C$

$\square$ AC+BAY41-2272

Figure 1 (a-c) Effects of BAY 41-2272 on systolic (a) and diastolic (b) blood pressure levels and heart rate (c). (d and e) Effects of BAY41-2272 on heart weight/body weight $(\mathbf{d})$ and cross-sectional area of myocardial fibers (e). Open circle $(\bigcirc)$, closed circle $(\bullet)$ and open square $(\square)$ indicate the control, aortic constriction (AC) and AC plus BAY 41-2272 treatment, respectively. ${ }^{* *} P<0.01$, compared with the controls. Values are shown as the means \pm s.e.m. of four rats (for blood pressure and heart rate) and of 11-21 rats (for heart weight, cross-sectional area of myocardial fibers) in the respective group. 
insulin, $5 \mu \mathrm{g} \mathrm{ml}^{-1}$ transferrin and $7 \mathrm{ng} \mathrm{ml}^{-1}$ sodium selenite at $37^{\circ} \mathrm{C}$ in a $95 \%$ air $/ 5 \% \mathrm{CO}_{2}$ humidified atmosphere. After achieving confluence, they were further incubated in serum-free Dulbecco's modified Eagle's medium containing the same additives for $48 \mathrm{~h}$. The cells were then cultured with BAY 41-2272 $\left(10^{-6}\right.$ and $\left.10^{-5} \mathrm{moll}^{-1}\right)$ or non-hydrolysable cGMP analog 8-bromo cGMP $\left(10^{-4}\right.$ and $\left.10^{-3} \mathrm{moll}^{-1}\right)$ (Calbiochem, San Diego, CA, USA) dissolved in dimethyl sulfoxide for a further $24 \mathrm{~h}$. The same volume of dimethyl sulfoxide was added to the control culture medium, and the final concentration of dimethyl sulfoxide did not exceed $0.1 \%$ in the culture medium. Thereafter, the cells were collected, and total protein was extracted for western blot as described earlier. ${ }^{24}$ In addition, they were extracted to measure ACE activity as described below. The extracted proteins were stored at $-80^{\circ} \mathrm{C}$ until use. a

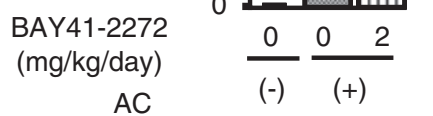

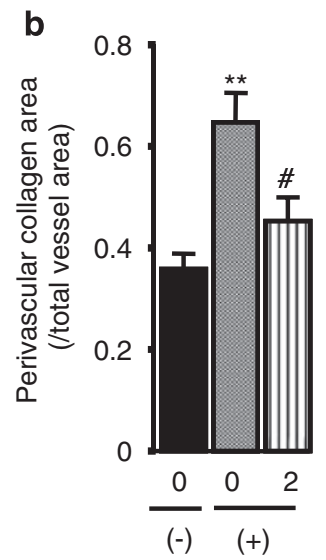
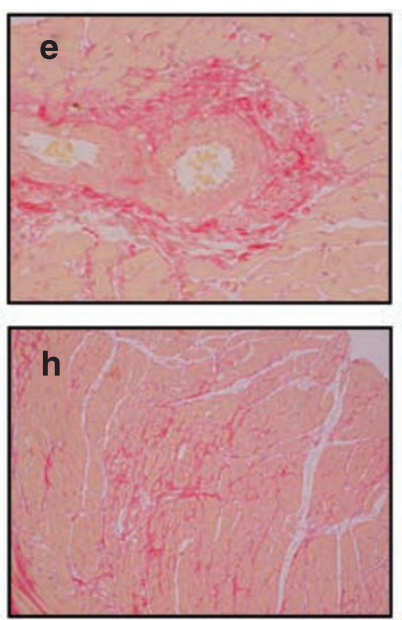

AC
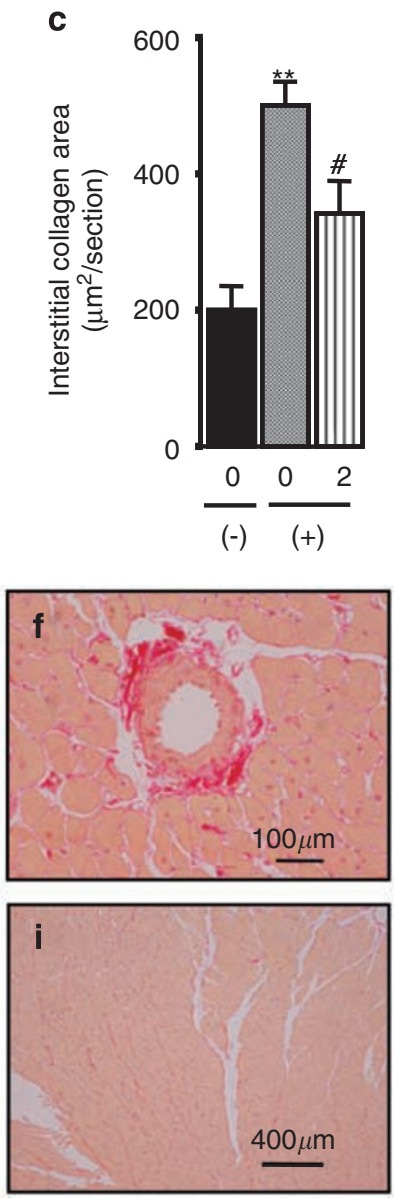

$A C+B A Y 41-2272$

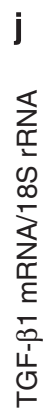

BAY41-2272

(mg/kg/day)
$\mathrm{AC}$

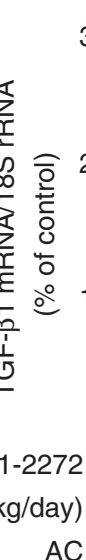

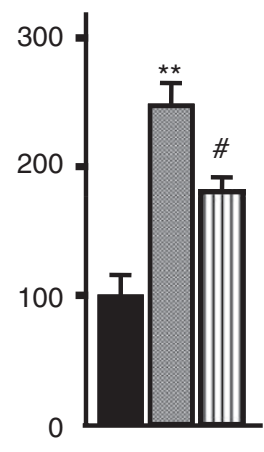

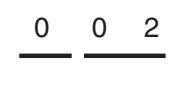

$(-) \quad(+)$

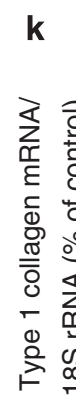

BAY41-2272

(mg/kg/day)

AC

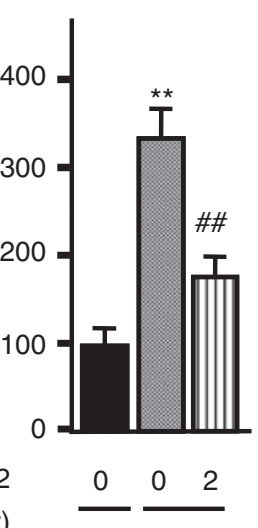

$(-) \quad(+)$

Figure 2 (a-c) Effects of BAY 41-2272 on the number of myofibroblasts determined by positive staining for $\alpha$-SMA (a), picrosirius red-positive areas in adventitia of intramyocardial coronary arteries (b) and myocardial interstitium (c). The panels are representative images of picrosirius red staining in the control ( $\mathbf{d}$ and $\mathbf{g}$ ) and aortic constriction (AC) rats without (e and $\mathbf{h}$ ) or with ( $\mathbf{f}$ and $\mathbf{i})$ BAY 41-2272 treatment. ( $\mathbf{j}$ and $\mathbf{k}$ ) Effects of BAY 41-2272 on gene expressions for transforming growth factor- $\beta 1$ (j) and type 1 collagen (k). Values are shown as the means \pm s.e.m. of 9-19 samples in the respective group.

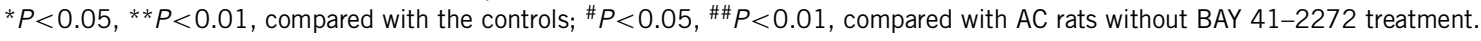


Cardiac myocytes were also isolated from 1- to 3-day-old neonatal Wistar rats as described earlier. ${ }^{26}$ After culturing the cells under the serum-free Dulbecco's modified Eagle's medium containing $10 \mu \mathrm{g} \mathrm{ml}^{-1}$ insulin, $5 \mu \mathrm{g} \mathrm{ml}^{-1}$ transferrin and $7 \mathrm{ng} \mathrm{ml}^{-1}$ sodium selenite for $48 \mathrm{~h}$, BAY 41-2272 $\left(10^{-6}\right.$ and $\left.10^{-5} \mathrm{moll}^{-1}\right)$ was then added to the medium to examine the intracellular cGMP elevation.

\section{Western blot}

Denatured total protein obtained from cultured cardiac fibroblasts was subjected to SDS-polyacrylamide gel as described earlier. ${ }^{12}$ In brief, the separated proteins electrically transferred onto polyvinylidine difluoride membranes were incubated with 5\% skim milk. Polyvinylidine difluoride membranes were then incubated with monoclonal antibody against the $\alpha$-SMA (1:2000, DakoCytomation) or with polyclonal antibody against the ACE (1:1000, Santa Cruz Biotechnology), followed by incubation with horseradish peroxidase-coupled second antibody. Immunoreactive bands were visualized by the ECL Plus detection kit (GE Healthcare, Buckinghamshire, UK) and band intensities were analyzed densitometrically (Chemi Doc Documentation System, Bio-Rad, Hercules, CA, USA). Coomassie blue staining was used as a protein-loading control.

\section{Radioimmunoassay}

Angiotensin II concentration in the LV was measured by radioimmunoassay, following extraction with a Sep-Pak C18 cartridge (Waters Corporation, Milford, MA, USA), as described earlier. ${ }^{18,27}$ Cultured cardiac fibroblasts and myocytes treated with or without BAY 41-2272 for 10 min were immediately collected, and the cGMP content was determined using a radioimmunoassay kit (YAMASA Cyclic GMP Assay Kit, Choshi, Japan). ${ }^{18}$

\section{ACE activity}

The LV tissues in the respective groups were homogenized in phosphatebuffered saline. Cultured cardiac fibroblasts treated with or without BAY 412272 or 8 -bromo cGMP for $24 \mathrm{~h}$ were collected in $1.8 \%$ Triton-X containing phosphate-buffered saline, and were lysed by freezing-thawing three times every $10 \mathrm{~min}$. The homogenized LV tissues or cell lysates were centrifuged at $10000 \mathrm{~g}$ for $10 \mathrm{~min}, 4{ }^{\circ} \mathrm{C}$ ACE activity in the supernatants was measured with a commercially available kit (ACE Color, Fujirebio Inc. Tokyo, Japan).

\section{Protein concentration}

Protein concentrations of LV tissues and cultured cells were determined with BCA Protein Assay Reagent (Pierce, Rockland, IL, USA), following the manufacturer's instructions.

\section{Statistical analysis}

All data were analyzed with SPSS software version 11.0 (SPSS Inc., Chicago, IL, USA). Values are expressed as the means \pm s.e.m. Differences between two groups were analyzed by Student's $t$-test, and differences between three groups a

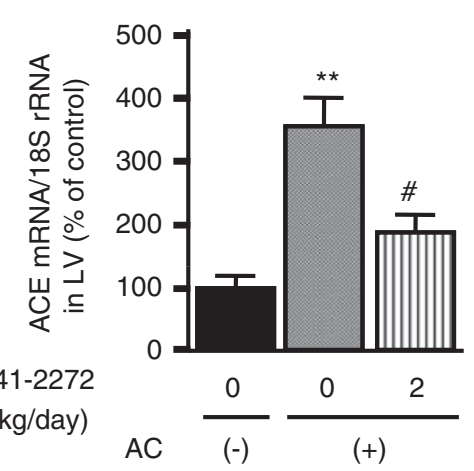

b

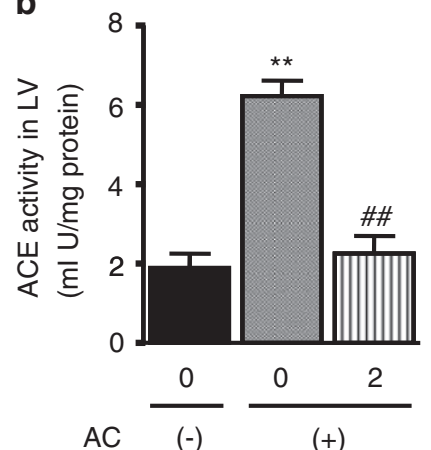

C

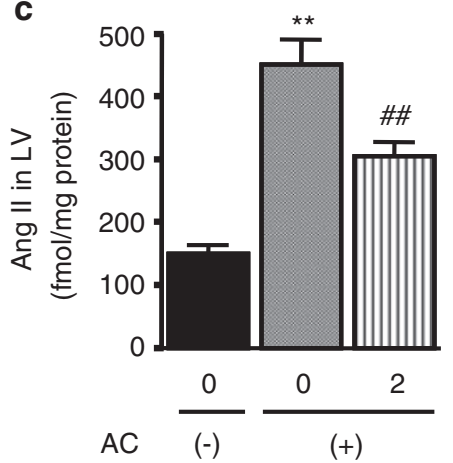

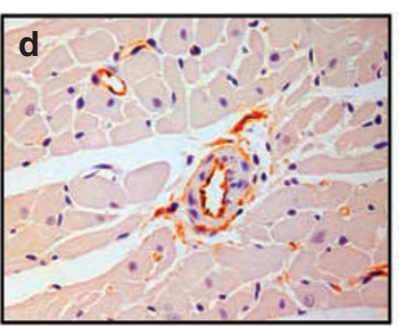
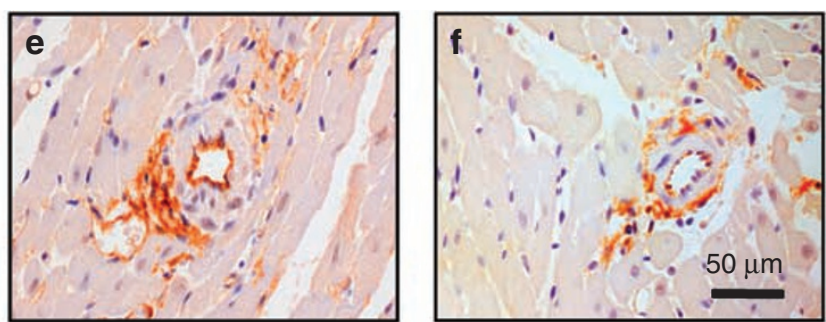

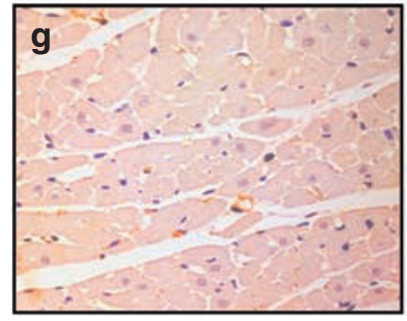

Control

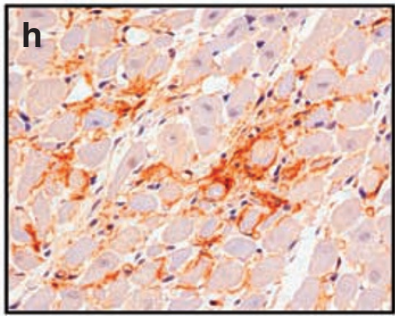

$\mathrm{AC}$

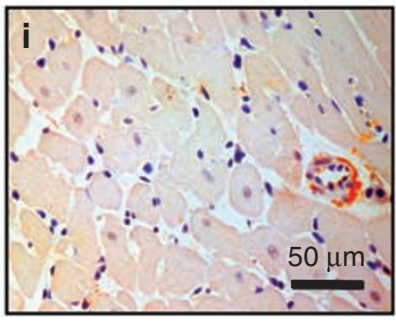

$A C+B A Y 41-2272$

Figure 3 (a-c) Effects of BAY 41-2272 on angiotensin-converting enzyme (ACE) mRNA level (a), ACE activity (b) and Ang II concentration (c) in the left ventricle (LV). The panels are representative images of ACE immunoreactivity in the control (d and $\mathbf{g}$ ) and aortic constriction (AC) rats without (e and $\mathbf{h})$ or with (f and i) BAY 41-2272 treatment. Bar: 50 $\mu \mathrm{m}$. Values are shown as the means \pm s.e.m. of $11-16$ in the respective group. ${ }^{* *} P<0.01$, compared with the controls; ${ }^{\#} P<0.05,{ }^{\#} P<0.01$, compared with AC rats without BAY 41-2272. 
were assessed using one-way analysis of variance followed by Scheffe's test, and statistical significance was accepted at $P<0.05$. In western blot analysis, standard curves were made by serial dilution of samples, and bands on gels were quantified based on the optical density.

\section{RESULTS}

Hemodynamics, heart weight and cardiocyte size

Figures $1 \mathrm{a}-\mathrm{c}$ show the blood pressure and heart rate in the controls and $\mathrm{AC}$ rats with or without BAY 41-2272 treatment. AC progressively raised systolic and diastolic blood pressure levels; however, BAY 412272 had no effect on the AC-induced elevation of blood pressure. Heart rate was unchanged in the respective groups. As shown in Figures $1 \mathrm{~d}$ and e, AC significantly $(P<0.01)$ increased the ratio of heart weight to body weight (HW/BW) and the crosssectional area of myocardial fibers, compared with the controls; however, BAY 41-2272 did not affect the AC-induced increase in HW/BW and cardiocyte size.

\section{Myofibroblasts and collagen deposition}

Figures $2 \mathrm{a}-\mathrm{c}$ show that $\mathrm{AC}$ increased the number of myofibroblasts and collagen depositions in the perivascular and the interstitial areas of LV, but BAY 41-2272 administration significantly $(P<0.05)$ decreased them by 88,30 and $46 \%$, respectively. Representative collagen deposition in the respective groups are shown in Figures $2 \mathrm{~d}-\mathrm{i}$. As shown in Figures $2 \mathrm{j}$ and $\mathrm{k}$, BAY 41-2272 administration significantly $(P<0.05)$ attenuated the AC-induced elevation of gene expressions of TGF- $\beta 1$ and type 1 collagen.

\section{Ang II synthesis}

Figure $3 \mathrm{a}$ and $\mathrm{b}$ show that $\mathrm{AC}$ significantly $(P<0.01)$ increased the gene expression and activity of ACE in LV, but BAY 41-2272 significantly $(P<0.01)$ reduced them by 47 and $64 \%$, respectively. Figure 3c shows that BAY 41-2272 administration significantly $(P<0.01)$ attenuated the AC-induced increase of Ang II concentration in $\mathrm{LV}$ by $36 \%$. As shown in Figures $3 \mathrm{~d}-\mathrm{i}$, ACE immunoreactivity
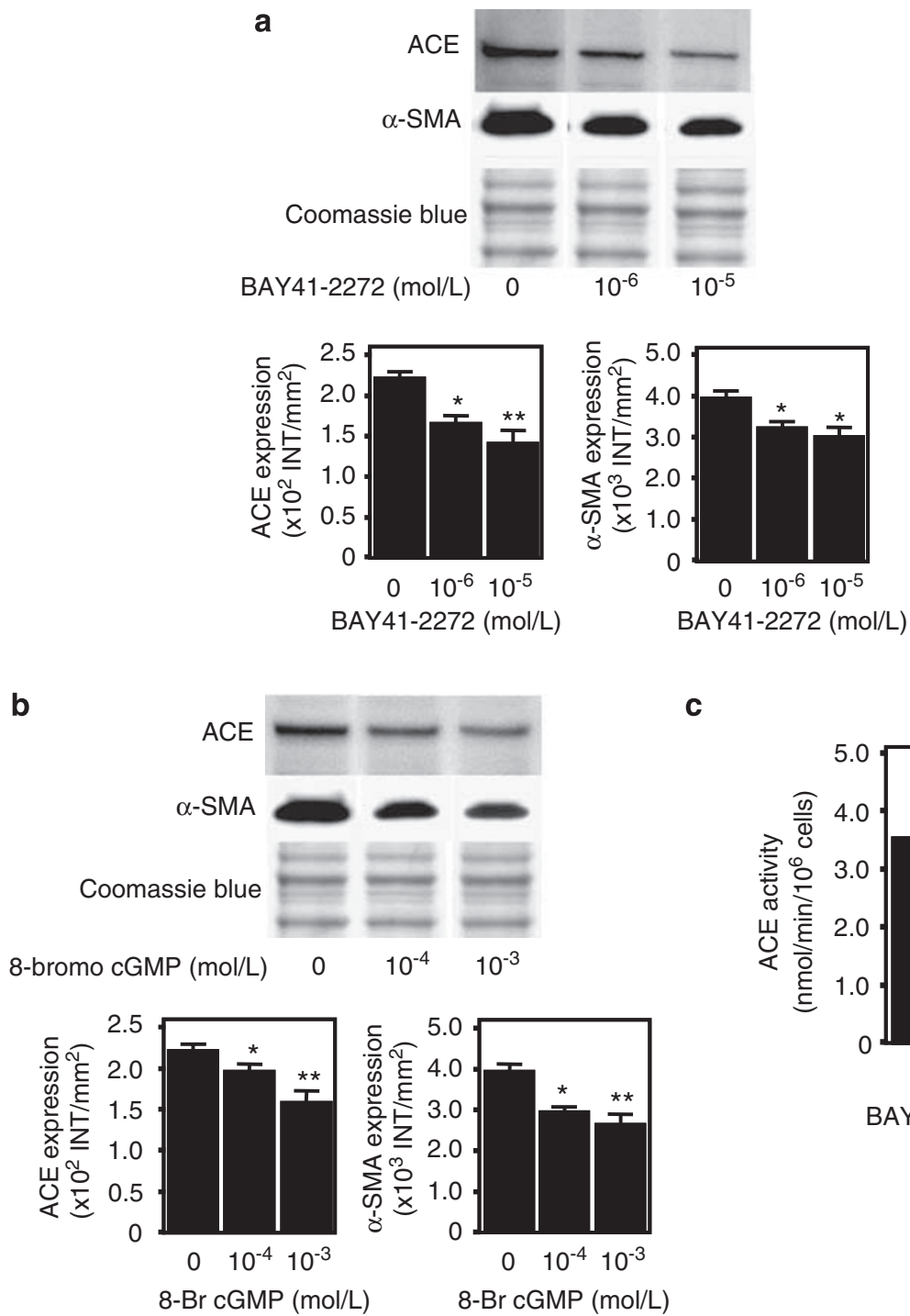

C

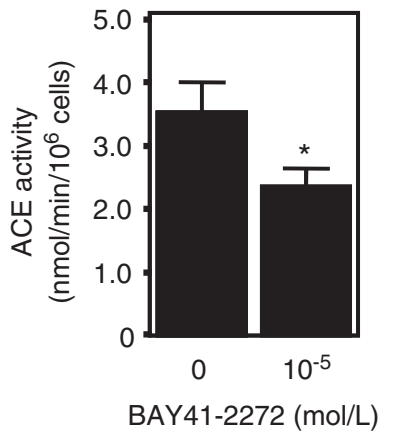

Figure 4 (a and b) Effects of BAY 41-2272 (a) and cGMP analog 8-bromo cGMP (b) on the protein expressions of angiotensin-converting enzyme (ACE) and $\alpha$-smooth muscle actin ( $\alpha$-SMA) in cultured cardiac fibroblasts. (c) Effect of BAY 41-2272 on ACE activity in cell lysates. The panels show representative images of western blotting, and values are shown as the means \pm s.e.m. of $4-6$ (a and $\mathbf{b}$ ), 9 and 11 (c) samples examined. ${ }^{*} P<0.05$, ${ }^{* *} P<0.01$, compared with control cells without either BAY 41-2272 or 8-bromo cGMP. Coomassie blue was used as the protein loading control. 

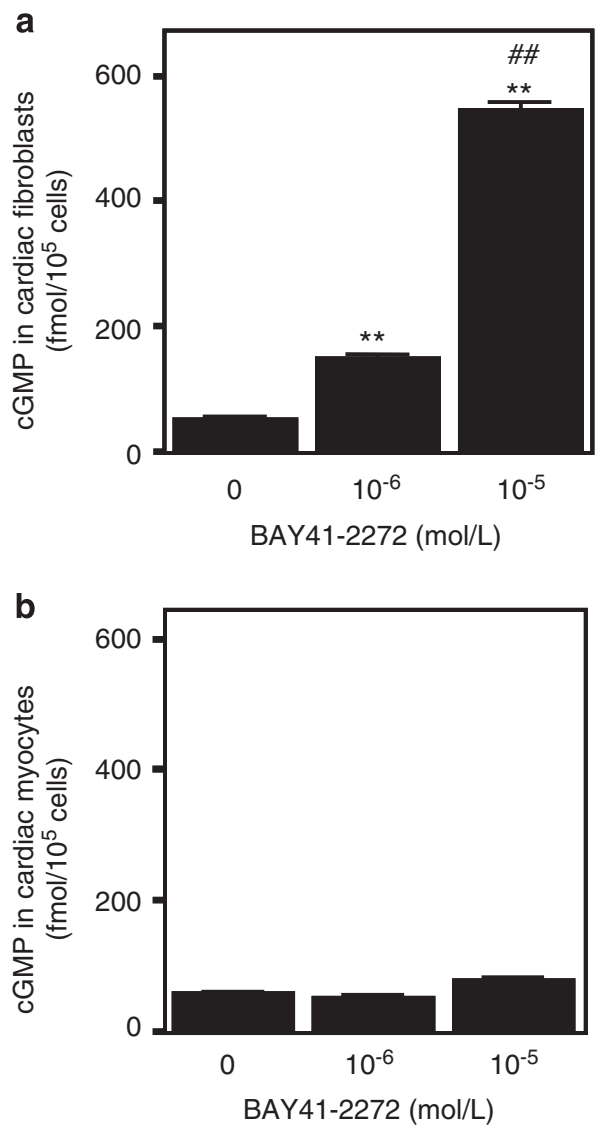

Figure 5 (a and $\mathbf{b}$ ) Effect of BAY 41-2272 on the intracellular cGMP level in cultured cardiac fibroblasts (a) and cardiac myocytes (b). Values are shown as the means \pm s.e.m. of 4 (a) and 8 (b) samples examined. ${ }^{* *} P<0.01$, compared with control cells without BAY 41-2272, \#\# $P<0.01$, compared with $10^{-6} \mathrm{~mol} \mathrm{I}^{-1}$ BAY 41-2272.

increased to localize in the perivascular and interstitial fibroblasts of $\mathrm{AC}$ rats, while it was decreased by treatment.

\section{ACE and $\alpha$-SMA in cultured cardiac fibroblasts}

Figure $4 \mathrm{a}$ shows that the protein expressions of ACE and $\alpha$-SMA were significantly decreased by $10^{-6}$ and $10^{-5} \mathrm{moll}^{-1}$ BAY41-2272 in cultured cardiac fibroblasts. In addition, a cGMP analog, 8-bromo cGMP $\left(10^{-4}\right.$ and $\left.10^{-3} \mathrm{moll}^{-1}\right)$ significantly reduced these protein expressions in the cells (Figure $4 \mathrm{~b}$ ). Furthermore, ACE activity was significantly $(P<0.05)$ decreased by $10^{-5} \mathrm{moll}^{-1}$ BAY $41-2272$ (Figure 4c).

cGMP level in cultured cardiac fibroblasts and myocytes As shown in Figure 5a, the intracellular cGMP level was significantly $(P<0.01)$ elevated by $10^{-5}$ and $10^{-6}$ moll ${ }^{-1}$ BAY $41-2272$ in cultured cardiac fibroblasts. On the other hand, the change of cGMP level in response to BAY $41-2272\left(10^{-5}\right.$ and $\left.10^{-6} \mathrm{moll}^{-1}\right)$ was minimal in cultured cardiac myocytes (Figure 5b).

\section{DISCUSSION}

This study shows the beneficial action of sGC stimulator BAY 41-2272 on attenuating fibrosis in a hypertrophied heart induced by pressure overload, independently of blood pressure. In addition, the inhibition of myofibroblast transformation and RAS activation appear be involved in this mechanism.
We have earlier reported that the depressor dose of sGC stimulation with BAY 41-2272 was effective to decrease cardiocyte hypertrophy and fibrosis, but the sub-depressor dose exhibited to decrease fibrosis without reducing cardiocyte hypertrophy in the Ang II-induced hypertensive model. ${ }^{18}$ This study was consistent to show that the sub-depressor dose of this compound decreased the fibrosis without altering cardiocyte hypertrophy defined by HW/BW and crosssectional area of myocardial fiber in the model of pressure overload. Although precise mechanisms by which the sub-depressor dose of sGC stimulation facilitates to decrease fibrosis remain to be elucidated, we might speculate the discrepancy between fibrosis and heart weight in response to the sGC stimulation by the following two reasons: (1) mechanical load is a major contributor to cardiocyte hypertrophy, ${ }^{7}$ and therefore the sub-depressor dose BAY 41-2272 was insufficient to influence the cardiocyte hypertrophy induced by pressure-overload; (2) in vitro experiment suggests that cardiac fibroblasts appear to be more feasible to exert cGMP elevation than cardiac myocytes by the compound. Using a sub-depressor dose of BAY 41-2272, the attenuation of fibrosis by this compound was associated with the reduction of TGF- $\beta 1$ and type 1 collagen expressions. TGF- $\beta 1$ is reported to be an important trigger to exert the phenotypic change of fibroblasts to myofibroblasts, a central player in exaggerating the production of extracellular matrix proteins, including type 1 collagen and fibronection. $^{28}$ On the other hand, sGC stimulation has been shown to attenuate/prevent fibrosis in various organs, such as the lungs, liver and kidneys; ${ }^{20,29-31}$ therefore, we examined whether this compound would decrease fibrosis by inhibiting the phenotypic change in fibroblasts. In line with our hypothesis, this study suggests the counter-regulatory action of BAY 41-2272 on the fibrotic process by inhibiting TGF- $\beta 1$ gene expression, concomitant with attenuating myofibroblast transformation in the pressure-overloaded heart. The model of pressure overload induced by constricting the suprarenal abdominal aorta has been reported to exhibit the substantial RAS activation in the heart, while the circulating RAS was less affected, ${ }^{21,22,32,33}$ suggesting that Ang II generation in the LV is likely to be associated with the progression of fibrosis. It is noted that BAY 41-2272 administration to AC rats has been shown to lower ACE gene expression and its activity, a main enzyme for Ang II generation in rats. ${ }^{34,35}$ Accordingly, this compound decreased the AC-induced increase of Ang II concentration in the LV. Consistent with earlier reports, ${ }^{34,35}$ ACE immunoreactivity showed increased distribution in the perivascular and interstitial fibroblasts of pressure-overloaded LV, whereas the distribution was diminished by BAY 41-2272 treatment. Various stimuli have been shown to stimulate ACE synthesis in the cardiovascular system, ${ }^{36,37}$ in which activity was increased during myofibroblast transformation in cultured cardiac fibroblasts. ${ }^{38}$ Therefore, we further tested whether BAY 41-2272 could affect ACE synthesis directly, and if so, whether it is associated with phenotypic change in cultured cardiac fibroblasts. Isolated fibroblasts have been shown to express $\alpha$-SMA, indicating myofibroblasts. As shown, BAY 41-2272 decreased the protein expressions of ACE and $\alpha$-SMA in these cells, accompanied by intracellular cGMP elevation. In addition, 8-bromo cGMP, an analog of cGMP, mimicked the effect of BAY 41-2272, inhibiting these expressions. More importantly, BAY 41-2272 has been shown to decrease ACE activity in these cells. These results support our in vivo observations, which sGC stimulation with BAY 41-2272 could inhibit ACE synthesis and activity, accompanied by regulating the fibroblast phenotype. We have earlier reported that BAY 41-2272 was capable of inhibiting cardiac fibroblast proliferation under Ang II stimulation. ${ }^{18}$ Taken together, we propose that pharmacological intervention with the orally 
effective sGC stimulator BAY 41-2272 points to an antifibrotic action, in which the inhibition of myofibroblasts transformation and Ang II synthesis might induce specific benefits against the development of hypertensive heart disease.

In summary, sGC stimulation with BAY 41-2272 attenuated cardiac fibrosis independently of blood pressure, and the inhibition of myofibroblast transformation and Ang II synthesis appear to be the potential mechanisms involved. Thus, our present study supports the sGC-cGMP-dependent beneficial action against adverse cardiovascular remodeling associated with hypertension. Further studies are warranted to clarify the long-term benefit and safety of this compound for future's clinical practice.

\section{CONFLICT OF INTEREST}

Toshihiro Tsuruda received a research grant from Bayer HealthCare. BAY 41-2272 was synthesized at Bayer HealthCare as a research tool but not for use in humans.

\section{ACKNOWLEDGEMENTS}

We thank Ms Ritsuko Sotomura for technical assistance. This study was supported by Grants-in-aid for Scientific Research (C) (20590830) from the Ministry of Education, Culture, Sports, Science, and Technology, Japan and from Bayer HealthCare.

1 Levy D, Larson MG, Vasan RS, Kannel WB, Ho KK. The progression from hypertension to congestive heart failure. JAMA 1996; 275: 1557-1562.

2 Kai H, Kuwahara F, Tokuda K, Imaizumi T. Diastolic dysfunction in hypertensive hearts: roles of perivascular inflammation and reactive myocardial fibrosis. Hypertens Res 2005; 28: 483-490.

3 Diamond JA, Phillips RA. Hypertensive heart disease. Hypertens Res 2005; 28: 191-202.

4 Müller-Brunotte R, Kahan T, López B, Edner M, González A, Díez J, Malmqvist K. Myocardial fibrosis and diastolic dysfunction in patients with hypertension: results from the Swedish Irbesartan Left Ventricular Hypertrophy Investigation versus Atenolol (SILVHIA). J Hypertens 2007; 25: 1958-1966.

5 Díez J, Querejeta R, López B, González A, Larman M, Martínez Ubago JL. Losartandependent regression of myocardial fibrosis is associated with reduction of left ventricular chamber stiffness in hypertensive patients. Circulation 2002; 105: 2512-2517.

6 McLenachan JM, Dargie HJ. Ventricular arrhythmias in hypertensive left ventricular hypertrophy. Relationship to coronary artery disease, left ventricular dysfunction, and myocardial fibrosis. Am J Hypertens 1990; 3: 735-740.

7 Weber KT. Fibrosis and hypertensive heart disease. Curr Opin Cardiol 2000; 15: 264 272.

8 Brilla CG, Funck RC, Rupp H. Lisinopril-mediated regression of myocardial fibrosis in patients with hypertensive heart disease. Circulation 2000; 102: 1388-1393.

9 Calderone A, Thaik CM, Takahashi N, Chang DL, Colucci WS. Nitric oxide, atrial natriuretic peptide, and cyclic GMP inhibit the growth-promoting effects of norepinephrine in cardiac myocytes and fibroblast. J Clin Invest 1998; 101: 812-818.

10 Mori T, Chen YF, Feng JA, Hayashi T, Oparil S, Perry GJ. Volume overload results in exaggerated cardiac hypertrophy in the atrial natriuretic peptide knockout mouse. Cardiovasc Res 2004; 61: 771-779.

11 Cao L, Gardner DG. Natriuretic peptides inhibit DNA synthesis in cardiac fibroblasts. Hypertension 1995; 25: 227-234.

12 Tsuruda T, Boerrigter G, Huntley BK, Noser JA, Cataliotti A, Costello-Boerrigter LC, Chen $\mathrm{HH}$, Burnett Jr JC. Brain natriuretic peptide is produced in cardiac fibroblasts and induces matrix metalloproteinases. Circ Res 2002; 91: 1127-1134.

13 Tamura N, Ogawa Y, Chusho H, Nakamura K, Nakao K, Suda M, Kasahara M, Hashimoto R, Katsuura G, Mukoyama M, Itoh H, Saito Y, Tanaka I, Otani H, Katsuki M. Cardiac fibrosis in mice lacking brain natriuretic peptide. Proc Natl Acad Sci USA 2000; 97: 4239-4244.

$14 \mathrm{Kim}$ NN, Villegas S, Summerour SR, Villarreal FJ. Regulation of cardiac fibroblast extracellular matrix production by bradykinin and nitric oxide. J Mol Cell Cardiol 1999; 31: 457-466.
15 Stasch JP, Becker EM, Alonso-Alija C, Apeler H, Denbowsky K, Feurer A, Gerzer R, Minuth T, Perzborn E, Pleiß U, Schröder H, Schroeder W, Stahl E, Steinke W, Straub A, Schramm M. NO-independent regulatory site on soluble guanylate cyclase. Nature 2001; 410: 212-215.

16 Boerrigter G, Costello-Boerrigter LC, Cataliotti A, Tsuruda T, Harty GJ, Lapp H, Stasch $\mathrm{JP}$, Burnett Jr JC. Cardiorenal and humoral properties of a novel direct soluble guanylate cyclase stimulator BAY41-2272 in experimental congestive heart failure. Circulation 2003; 107: 686-689.

17 Evgenov OV, Ichinose F, Evgenov NV, Gnoth MJ, Falkowski GE, Chang Y, Bloch KD, Zapol WM. Soluble guanylate cyclase activator reverses acute pulmonary hypertension and augments the pulmonary vasodilator response to inhaled nitric oxide in awake lambs. Circulation 2004; 110: 2253-2259.

18 Masuyama H, Tsuruda T, Kato J, Imamura T, Asada Y, Stasch JP, Kitamura K, Eto T. Soluble guanylate cyclase stimulation on cardiovascular remodeling in angiotensin IIinduced hypertensive rats. Hypertension 2006; 48: 972-978.

19 Yan C, Kim D, Aizawa T, Berk BC. Functional interplay between angiotensin II and nitric oxide: cyclic GMP as a key mediator. Arterioscler Thromb Vasc Biol 2003; 23: 26-36.

20 Dunkern TR, Feurstein D, Rossi GA, Sabatini F, Hatzelmann A. Inhibition of TGF- $\beta$ induced lung fibroblast to myofibroblast conversion by phosphodiesterase inhibiting drugs and activators of soluble guanylyl cyclase. Eur J Pharmacol 2007; 572: 12-22.

21 Kuwahara F, Kai H, Tokuda K, Kai M, Takeshita A, Egashira K, Imaizumi T. Transforming growth factor- $\beta$ function blocking prevents myocardial fibrosis and diastolic dysfunction in pressure-overloaded rats. Circulation 2002; 106: 130-135.

22 Hirano S, Imamura T, Onitsuka H, Matsuo T, Kitamura K, Koiwaya Y, Eto T. Rapid increase in cardiac adrenomedullin gene expression caused by acute pressure overload: effect of the renin-angiotensin system on gene expression. Circ J 2002; 66: 397-402.

23 Tonkiss J, Trzcivska M, Galler JR, Ruiz-Opazo N, Herrera VLM. Prenatal malnutritioninduced changes in blood pressure. Dissociation of stress and nonstress responses using radiotelemetry. Hypertension 1998; 32: 108-114.

24 Tsuruda T, Kato J, Hatakeyama K, Masuyama H, Cao YN, Imamura T, Kitamura K, Asada $Y$, Eto T. Antifibrotic effect of adrenomedullin on coronary adventitia in angiotensin II-induced hypertensive rats. Cardiovasc Res 2005; 65: 921-929.

25 Naito Y, Tsujino T, Fujioka Y, Ohyanagi M, Iwasaki T. Augmented diurnal variations of the cardiac renin-angiotensin system in hypertensive rats. Hypertension 2002; 40: 827-833.

26 Tsuruda T, Kato J, Kitamura K, Kuwasako K, Imamura T, Koiwaya Y, Tsuji T, Kangawa K, Eto T. Adrenomedullin: a possible autocrine or paracrine inhibitor of hypertrophy of cardiomyocytes. Hypertension 1998; 31: 505-510.

27 Nagata S, Kato J, Sasaki K, Minamino N, Eto T, Kitamura K. Isolation and identification of proangiotensin-12, a possible component of the renin-angiotensin system. Biochem Biophys Res Commun 2006; 350: 1026-1031.

28 Powell DW, Mifflin RC, Valentich JD, Crowe SE, Saada JI, West AB. Myofibroblasts. I. Paracrine cells important in health and disease. Am J Physiol 1999; 277: C1-C9.

29 Wang Y, Krämer S, Loof T, Martini S, Kron S, Kawachi H, Shimizu F, Neumayer HH, Peters $\mathrm{H}$. Enhancing cGMP in experimental progressive renal fibrosis: soluble guanylate cyclase stimulation vs phosphodiesterase inhibition. Am J Physiol Renal Physiol 2006; 290: F167-F176.

30 Kalk P, Godes M, Relle K, Rothkegel C, Hucke A, Stasch JP, Hocher B. NO-independent activation of soluble guanylate cyclase prevents disease progression in rats with $5 / 6$ nephrectomy. Br J Pharmacol 2006; 148: 853-859.

31 Knorr A, Hirth-Dietrich C, Alonso-Alija C, Härter M, Hahn M, Keim Y, Wunder F, Stasch JP. Nitric oxide-independent activation of soluble guanylate cyclase by BAY $60-2770$ in experimental liver fibrosis. Arzneimittelforschung 2008; 58: 71-80.

32 Tokuda K, Kai H, Kuwahara F, Yasukawa H, Tahara N, Kudo H, Takemiya K, Koga M, Yamamoto T, Imaizumi T. Pressure-independent effects of angiotensin II on hypertensive myocardial fibrosis. Hypertension 2004; 43: 499-503.

33 Kobayashi S, Yano M, Kohno M, Obayashi M, Hisamatsu Y, Ryoke T, Ohkusa T, Yamakawa K, Matsuzaki M. Influence of aortic impedance on the development of pressure-overload left ventricular hypertrophy in rats. Circulation 1996; 94: 33623368.

34 Kurosawa $\mathrm{Y}$, Katoh M, Doi $\mathrm{H}$, Narita $\mathrm{H}$. Tissue angiotensin-converting enzyme activity plays an important role in pressure overload-induced cardiac fibrosis in rats. J Cardiovasc Pharmacol 2002; 39: 600-609.

35 de Lannoy LM, Schuijt MP, Saxena PR, Schalekamp MA, Danser AH. Angiotensin converting enzyme is the main contributor to angiotensin $|-| \mid$ conversion in the interstitium of the isolated perfused rat heart. J Hypertens 2001; 19: 959-965.

36 Barreto-Chaves ML, Anéas I, Krieger JE. Glucocorticoid regulation of angiotensinconverting enzyme in primary culture of adult cardiac fibroblasts. Am J Physiol Regul Integr Comp Physiol 2001; 280: R25-R32.

37 Saijonmaa O, Nyman T, Kosonen R, Fyhrquist F. Upregulation of angiotensin-converting enzyme by vascular endothelial growth factor. Am J Physiol Heart Circ Physiol 2001; 280: H885-H891.

38 Petrov VV, Fagard RH, Lijnen PJ. Transforming growth factor- $\beta 1$ induces angiotensinconverting enzyme synthesis in rat cardiac fibroblasts during their differentiation to myofibroblasts. J Renin Angiotensin Aldosterone Syst 2000; 1: 342-352. 